\title{
Exploring aspects of scientific publishing in astrophysics and cosmology: the views of scientists
}

\author{
Panayiota Polydoratou and Martin Moyle
}

University College London

\begin{abstract}
Scientists in astrophysics and cosmology make much use of the arXiv repository. Concerns raised by scientists in those fields about publication costs and delays, and the transparency and validity of the peer review process, raised questions about levels of satisfaction with existing publishing models. This paper discusses the results from a community survey in the fields of astrophysics and cosmology, conducted as part of an investigation into the feasibility of an "overlay journal" model in these disciplines. Six hundred and eighty three (683) researchers provided information about their academic/research background, their research practices, and their attitudes, both as producers and consumers of information, to the traditional journal publishing system, and gave their reaction to the overlay publication model. The survey results indicate that scientists in these disciplines are, in general, favourably disposed towards new publishing models, although some important caveats and concerns, particularly regarding quality, were highlighted.
\end{abstract}

\section{Introduction}

The Repository Interface for Overlaid Journal Archives (RIOJA) project (http://www.ucl.ac.uk/ls/rioja) is an international partnership of academic staff, librarians and technologists from UCL (University College London), the University of Cambridge, the University of Glasgow, Imperial College London and Cornell University. It aims to address the issues around the development and implementation of a new publishing model, the overlay journal - defined, for the purposes of the project, as a quality-assured journal whose content is deposited to and resides in one or more open access repositories. The project is funded by the Joint Information Systems Committee (JISC, http://www.jisc.ac.uk/), UK, and runs from April 2007 to June 2008.

The impetus for the RIOJA project came directly from academic users of the arXiv (http://arxiv.org) subject repository. For this reason, arXiv and its commu- 
2 Exploring aspects of scientific publishing in astrophysics and cosmology: the views of scientists2 Panayiota Polydoratou and Martin Moyle

nity is the testbed for RIOJA. arXiv was founded in 1991 to facilitate the exchange of pre-prints between physicists. It now holds over 460,000 scientific papers, and in recent years its coverage has extended to mathematics, nonlinear sciences, quantitative biology and computer science in addition to physics. arXiv is firmly embedded in the research workflows of these communities.

This paper discusses the results from a study which, as part of the RIOJA project, surveyed the views of scientists in the fields of astrophysics and cosmology regarding an overlay journal model. To gather background to their views on publishing, the respondents were asked to provide information about their research, publishing and reading patterns. The use of arXiv in this community and their response to a potential overlay publishing model were also in addressed in the survey. Respondents were asked to provide feedback about the suggested model; to indicate the factors that would influence them in deciding whether to publish in a journal overlaid onto a public repository; and to give their views on the relative importance of different features and functions of a journal in terms of funding priorities.

\section{Literature Review}

The overlay concept, and the term "overlay journal" itself, appear to be attributed to P. Ginsparg (1996). J W T Smith (1999) made a significant contribution to the concept of overlay journals by discussing and comparing functions of the existing publishing model with what he referred to as the "deconstructed journal". Although aspects of overlay have been introduced to journals in some subject domains, such as mathematics, overlay journals have not yet been widely deployed.

Halliday and Oppenheim (1999), in their report regarding the economics of Digital Libraries, recommended further research, in the field of electronic publishing in particular. Specifically, they suggested that the costs of electronic journal services should be further investigated, and commented that the degree of functionality that users require from electronic journals may have an impact on their costs.

Self-archiving and open access journals have been recommended by the Budapest Open Access Initiative (http://www.soros.org/openaccess/read.shtml) as the means to achieve access to publicly-funded research. The overlay model has the potential to combine both these "Green" (self-archiving) and "Gold" (open access journal) roads to open access. Hagemmann (2006) notes that overlay journals complement the original BOAI dual strategy for achieving Open Access..." and suggests that the overlay model could be the next step to open access. Factors such as the expansion of digital repositories, the introduction of open source journal management software, an increasing awareness within the scholarly community at large of the issues around open access, and an increasing readiness within the publishing community to experiment with new models, suggest that the circumstances may now be right for an overlay model to succeed. The RIOJA survey was designed to 
Methodology 3Exploring aspects of scientific publishing in astrophysics and cosmology: the views of scientists 3

test the reaction of one research community, selected for its close integration with a central subject repository, to this prospective new model.

\section{Aims and objectives}

The aims of the survey were to explore the feasibility of a new journal publishing model in the field of astrophysics and cosmology, and to gather structured community input towards the refinement of a demonstrator journal. In particular, the objectives were:

- To gain a snapshot of research practice in this discipline, with particular reference to information-seeking, repository use and publication.

- To explore the ideal functional requirements of a community-led journal in astrophysics and cosmology, in order to inform further investigation into the costs associated with a sustainable implementation of the RIOJA model.

- To identify factors critical to the successful academic take-up of a journal founded on the principle of overlaid quality certification.

\section{Methodology}

The RIOJA project is currently being carried out in six overlapping packages, addressing technical developments in support of the overlay model, as well as its sustainability. . This paper discusses the results from an online questionnaire survey, aiming to explore the views of scientists in the fields of astrophysics and cosmology on the feasibility of an overlay journal model. The Times Higher Education Supplement World Rankings was used to identify scientists in the top 100 academic and 15 non-academic institutions in the fields of astrophysics and cosmology, so as to receive feedback from the research community at an international level. Additionally, the invitation to participate in the survey was posted to a domain-specific discussion list, "CosmoCoffee" (http://www.cosmocoffee.info).

The survey was launched on June $8^{\text {th }} 2007$, and closed on July $15^{\text {th }}$. The questionnaire comprised 5 sections. The first section aimed to gather demographic and other background information about the respondents. Sections 2 and 3 were designed to gather information about the research norms and practices of the scientists, from their perspectives as both creators and readers of research. Section 4 aimed to identify issues around the researchers' use of arXiv; and the final section sought their views regarding the viability of the overlay journal model. The target group was restricted to scientists who have completed their doctoral studies, and who therefore could be assumed to have produced some publication of their research or to be in the process of publishing their research outcomes. 
4 Exploring aspects of scientific publishing in astrophysics and cosmology: the views of scientists4 Panayiota Polydoratou and Martin Moyle

\section{Definition and scope}

For the purpose of this paper an overlay journal is defined as a quality-assured journal whose content is deposited to and resides in one or more open access repositories

The chosen sample placed some limitations on the survey. Identifying and collecting contact details for the scientists proved to be a difficult and lengthy process, for various reasons. For instance, astrophysics research groups in academic institutions often conduct interdisciplinary research, and can be spread across more than one department such as physics, mathematics and astronomy. In most cases, contact details for scientists, academic and research staff were not disclosed on institutional Web sites, and visits to various additional Web pages were required. Additionally, academic institutions are dynamic organisations, and academic and research staff can hold positions in more than one institution. Some overlap of contacts was therefore inevitable, although duplication was avoided wherever possible. These limitations should be borne in mind when the survey results are considered.

\section{Results}

The following sections present the results from the online questionnaire survey. 4012 scientists were contacted, and six hundred and eighty three (683), or 17\%, responded.

\section{Some identity characteristics}

The first section of the questionnaire aimed to gather information that would allow the RIOJA team to draw an indicative profile of the scientists who participated in the questionnaire survey. In particular, almost a quarter of the responses came from scientists with professorial status ( 163 people, $24 \%$ of base $=683)$. This was followed by Research Fellows (135 people, 20\%), Lecturers (79 people, 12\%), Senior Research Fellows (81 people, 12\%) and Research Associates (81 people, $12 \%)$. The remainder of the response was divided between Readers, Senior Lecturers, and other categories. Almost half of the scientists $(46 \%)$ reported having over 10 years of post-doctoral research experience. The vast majority $(90 \%)$ indicated that their primary responsibility was research. Teaching (38\%) and heading a research group/unit (21\%) also featured highly as indicative responsibilities of the scientists. The English language was reported as the mother tongue of almost half $(51 \%)$ of respondents. 
Results 5Exploring aspects of scientific publishing in astrophysics and cosmology: the views of scientists 5

\section{Publishing research outputs and reading patterns in astrophysics and cosmology}

The second section of the questionnaire was designed to gather information about the information-seeking and publishing patterns of scientists in the fields of astrophysics and cosmology. The following issues were explored in particular:

- Whether scientists in those fields still require journals to publish their research.

- What factors affect their decisions on where to publish

The first choice of research output for the vast majority of the researchers (663 people) was papers for submission to peer-reviewed journals. The scientists reported that, on average, they each produced 13 papers over a two year period. The second most popular research output was papers for conference proceedings. Both of those findings confirm the importance that peer-reviewed journals and peers in general, play in the validation and dissemination of research in this discipline.

The journals in which the respondents had mostly published their research were: "The Astrophysical Journal" (476 people), "Monthly Notices of the Royal Astronomical Society" (382) and "Astronomy and Astrophysics" (331). These 3 journals are among the top 10 journals in terms of ISI impact factor. Irrespective of ongoing discussions in the literature about the validity of citation analysis, these findings indicate that it does currently have a bearing on scientists' decisions on where to publish.

The researchers were also asked to rank the importance of several factors which might influence their decision on where to publish. The majority of the researchers (494 people) reported that the quality of the journal as perceived by the scientific community was very important to them. Other important factors were the impact factor of the journal (330), and being kept up-to-date during the refereeing process (346). Factors that were deemed to range from neither important nor unimportant, to unimportant, were whether the journal is published by their professional society (473), and whether the journal is published in print (463). These results are presented in the following table. 
6 Exploring aspects of scientific publishing in astrophysics and cosmology: the views of scientists6 Panayiota Polydoratou and Martin Moyle

Table 1. Factors affecting the decision of where to publish

Statement

Perceived quality of the journal by the scientific community

High journal impact factor

Being kept up-to-date during the refereeing process

Other factors (please specify) Inclusion in indexing/abstracting services (e.g. ISI Science Citation Index)

Reputation of the editor/editorial board

Journals that do not charge authors for publication

Open Access Journals (journals whose content is openly and freely available)

Low or no subscription costs

Journals which publish a print version

Journals published by my professional society

Journals which have a high rate of rejection of papers

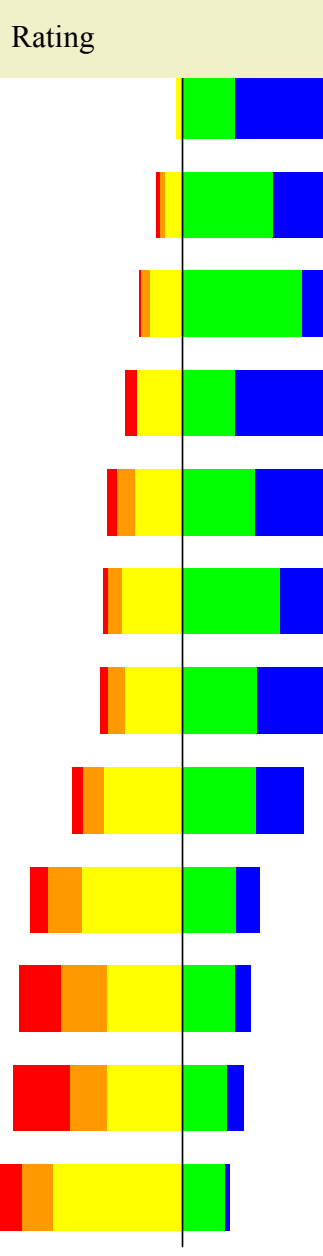

Key:

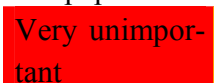

$\%$ agree

$\pm$

88.9

$\pm$ $81.6 \pm 3$ $75.3 \quad \pm \quad 9.4$ $\pm$ 67.9 3.6 $66.2 \quad \pm \quad 3.6$ $64.5 \pm 3.6$

$\pm$

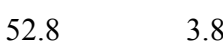

$33.9 \pm 3.6$

$29.8 \pm 3.5$

$26.9 \pm 3.4$

$\begin{array}{lll} & \pm & \\ 21.1 & \end{array}$

impor- Very important tant

Other factors that were specifed as important by respondents emphasised the process of peer review - in particular, the speed, quality and reliability of the process. Some comments on the speed of peer review concerned the role of the editorial team and other support services (e.g. publishers' role). Comments show that an easily accessible editorial team that keeps scientists informed at each stage of the review process while responding promptly and reliably to questions is desirable. Also welcomed, perhaps as an alternative, would be access to an online system that allows authors to keep track of the peer review process, supplemented by a clear statement how the review is conducted and the assessment criteria in place 
Results 7Exploring aspects of scientific publishing in astrophysics and cosmology: the views of scientists 7

Comments about the quality of peer review raised issues around the transparency of the process, the selection of the referees and a proven record of past refereeing alongside what a respondent called "respected peer review". Furthermore, comments also referred to the competence, care, efficiency and responsibility of editors and editorial boards. The subject coverage of the journal, the efficiency and ease of use of the submission system, handling of images and various file formats (eg LaTex), and the time that it takes for a paper to reach publication were also noted as influential factors.

\section{Use of the arXiv and other services}

The scientists were asked to indicate the means they employ for keeping up to date with advances in their fields. The majority of the respondents (549 people, $80.4 \%$ of base $=683$ ) visit the arXiv and in particular the "new/recent" section to keep up to date with new research. This finding confirms the role of the arXiv in these fields as an active and vital point for publicising research. In addition to arXiv's "new/recent" service, 396 people (58\%) noted that they visit the ADS website to look for new papers. This shows that indexing services still have a place in this community Those who noted "other" in their response mentioned their reliance on information from and discussions with colleagues, journal alerting services (such as RSS and table of contents), attendance at conferences and workshops, and visiting SPIRES.

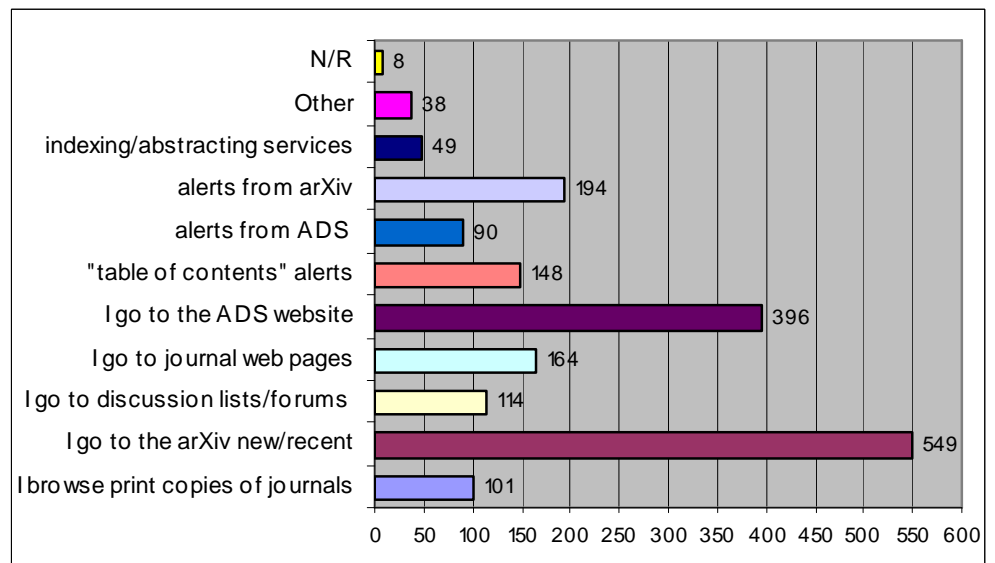

Fig. 1. Sources used for keeping up to date with research advances

The scientists were also asked to indicate the locations they turn to retrieve the full text of potentially interesting papers. E-print repositories (such as the arXiv) were denoted as the primary source of information for accessing the full text of a paper by 610 people $(89 \%$ of base $=683$, Fig. 2 . $)$. The second most-preferred option $(443$ 
8 Exploring aspects of scientific publishing in astrophysics and cosmology: the views of scientists8 Panayiota Polydoratou and Martin Moyle

scientists, $65 \%$ ) is to visit the journal's website.. Those who indicated "other" sources (111 people, 16.3\%) referred mainly to the ADS services and to SPIRES.

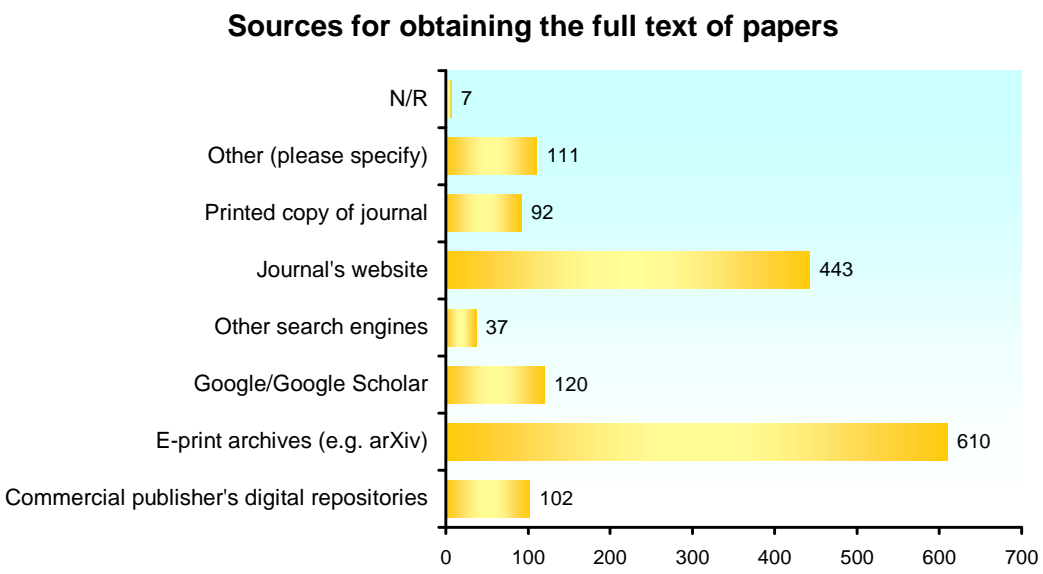

Fig. 2. Sources used for accessing the full text of papers

\section{Overlay journal model}

More than half of the respondents to the questionnaire survey (53\%) were favourably disposed to the overlay journal as a potential future model for scientific publishing. More than one third (35\%) of the respondent, however, noted that although an overlay journal model sounds interesting they did not consider it important: this group indicated that they were fairly satisfied with their current access to research outputs. A further $7 \%$ of the scientists either did not reply, or said they agreed with any of the options provided. 


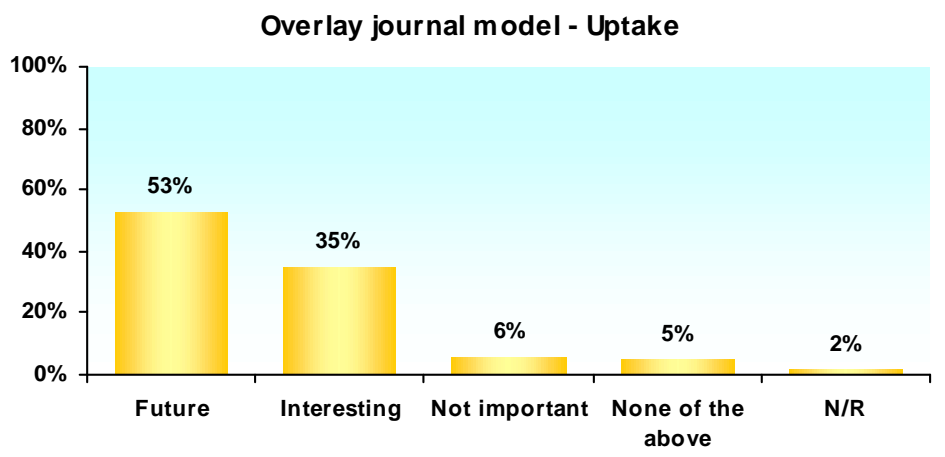

Fig. 3. Overlay journal model - Uptake

Many interesting comments were made in response to this question. Scientists who did not welcome the overlay journal model highlighted their currently unclear perception and understanding of the overlay journal model, and their concerns about new publishing models. Comments from all groups noted that forming an opinion about the possible role of overlay journal models in the future of publishing scientific journals would depend upon:

- “...how the journal was explicitly set-up in practice"

- “...I am concerned about long-term archiving, which assumes much greater importance when you are dealing with completed, peer-reviewed works as opposed to electronic preprints or open-access copies of material that is archived elsewhere"

- “...on how widely used by readers the system becomes. If no-one reads it, there's no point submitting to it"

- "An overlay of "accepted" papers is O.K. if the acceptance standards are objective"

- "if this is to replace all other journals, as it should, particular care has to be taken with the review process to allow authors to challenge the peer review or editor; parallel alternate structures need to be in place".

Additionally, concerns relating to the use of arXiv as the repository to be overlaid (policies about file sizes, submission, acceptance and citation of unrefereed papers, multiple versions of papers, etc.) were also raised by some of the respondents. For example:

- “...arXiv papers that are submitted before refereeing and then resubmitted 1-2 times are both annoying and scientifically irresponsible. If there was really a new category of arXiv that only had accepted papers, that is a plus, but even better would be to make it clearer to insist that papers should not even be posted on arXiv unless they have been reviewed..." 
10 Exploring aspects of scientific publishing in astrophysics and cosmology: the views of scientists10 Panayiota Polydoratou and Martin Moyle

- "arXiv allows for replacements. Journal would need to specify which version was peer reviewed and should be considered as "published". This may lead to confusion".

- "A point I have with this new idea is: will the "accepted" papers be in the same repository of the "normal" arXiv (so that it will not be that easy to find them) or will there be a devoted repository which keep them separated from the others?"

Respondents to the questionnaire survey were asked to provide their views about what fraction of money, within a given budget, should be spent on different functions of a journal. We used a ranking scale of five points, ranging from "none", to little (1) and very little (2), moderate amount (3), and considerable (4) and most of the amount (5), with the additional option of "not sure". It was hoped that this would provide some indication of which journal functions the scientists considered important; the question was not designed to be the basis of a costing exercise for a potential new journal. Most of the responses indicated that the scientists place importance on the role of scientific and copy editors and ensuring the maintenance of the journal software. However, the majority of the respondents in every group emphasised the importance of the journal website, with the online archive of the journal's back issues also given some priority.

Table 2. Suggested expenditure/priorities by journal functions

\begin{tabular}{llllllll}
\hline $\begin{array}{l}\text { Suggested expendi- } \\
\text { ture/priority }\end{array}$ & None & $\mathbf{1}$ & $\mathbf{2}$ & $\mathbf{3}$ & $\mathbf{4}$ & $\mathbf{5}$ & $\begin{array}{l}\text { Not } \\
\text { sure }\end{array}$ \\
\hline Paying scientific editors & 23 & 23 & 60 & 240 & 141 & 15 & 21 \\
\hline Paying copy editors & 8 & 28 & 73 & 256 & 134 & 6 & 15 \\
\hline $\begin{array}{l}\text { Maintenance of journal } \\
\text { software }\end{array}$ & 4 & 20 & 73 & 238 & 147 & 9 & 30 \\
\hline Journal website & 5 & 28 & 79 & 225 & 149 & 20 & 15 \\
\hline $\begin{array}{l}\text { Online archive of journal's } \\
\text { own back issues }\end{array}$ & 9 & 27 & 52 & 202 & 189 & 18 & 19 \\
\hline $\begin{array}{l}\text { Production of paper ver- } \\
\text { sion }\end{array}$ & 138 & 101 & 125 & 107 & 29 & 4 & 14 \\
\hline $\begin{array}{l}\text { Extra features such as } \\
\text { storage of associated data }\end{array}$ & 30 & 63 & 105 & 182 & 100 & 6 & 26 \\
\hline Publisher profits & 142 & 122 & 138 & 91 & 9 & 0 & 19 \\
\hline Paying referees & 249 & 70 & 70 & 85 & 22 & 8 & 18 \\
\hline Other & 3 & 1 & 1 & 1 & 3 & 2 & 3 \\
\hline
\end{tabular}

Finally, the respondents were asked to indicate the factors that would encourage them to publish in an overlay journal (as defined by the RIOJA project), and whether they would be willing to participate in an overlay journal in some capacity. The most important factors which would encourage publication were the qual- 
ity of other submitted papers (526), the transparency of the peer review process (410) and the reputation of the editorial board (386). They also provided a range of other factors that they considered important, among them the reputation of the journal; its competitiveness across other journals under the RAE (the UK's Research Assessment Exercise); the quality both of the journal's referees and of its accepted papers; a commitment to using free software; a commitment to the longterm archiving and preservation of published papers; relevant readership; acceptance and reputation of the journal in the scientific community; and its impact factor, which should only take into account citations to papers after final acceptance and not while residing on arXiv prior to "publication".

The questionnaire participants were asked to indicate their willingness, in principle, to participate in an arXiv-overlay journal. The vast majority of the scientists (549 people, $80 \%$ of base $=683$ ) stated that they would act as referees (Fig. 4. ). Given the emphasis that the researchers placed on the process of peer review, noted throughout this report, this result suggests that there is genuine interest in contributing to the improvement of what they consider an important process. A willingness to referee for an overlay journal was expressed by over three quarters of respondents in each group, with Readers the only exception at $68 \%$.

\section{Willingness to participate}

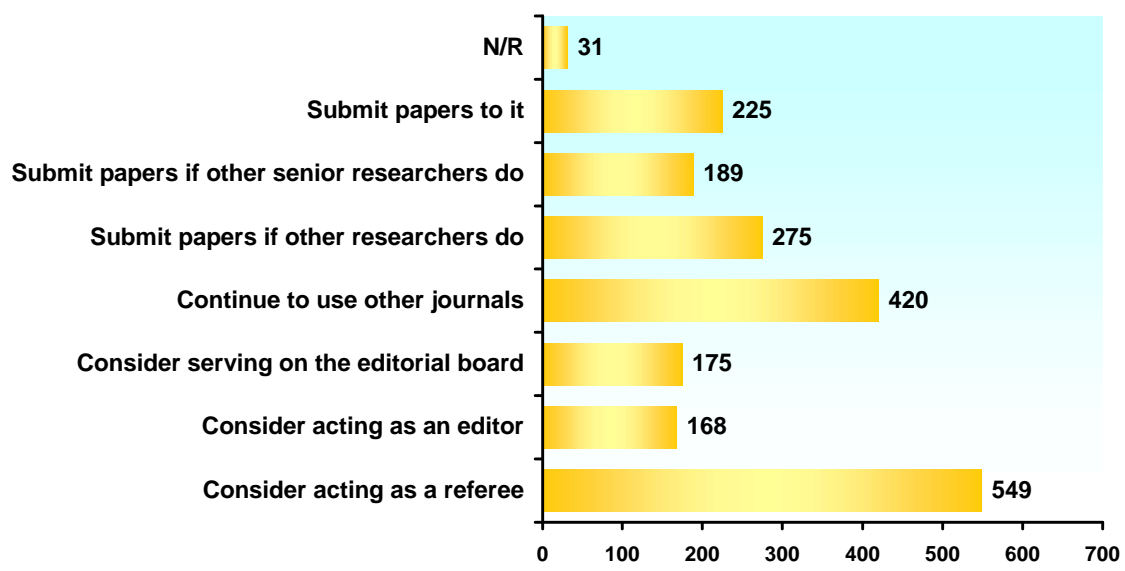

Fig. 4. Scientists' willingness to participate in an arXiv-overlay journal

\section{Conclusions and future work}

The roles, responsibilities and experience of the respondents primarily involve research. The preferred output from their research is peer-reviewed journal article, which confirms the importance in this discipline of certification by quality-assured 
12 Exploring aspects of scientific publishing in astrophysics and cosmology: the views of scientists12 Panayiota Polydoratou and Martin Moyle

journals. The scientists indicated that the quality of any journal publishing model is very important to them, and they choose to publish in journals that demonstrate to them the endorsement of the scientific community, whether through readership levels, impact factor, or perceived quality of the editorial board and journal content.

In general the scientists were disposed favourably towards the overlay journal model. However, they raised several implementation issues that they would consider important, primarily relating to the quality of the editorial board and of the published papers, and to the long-term archiving of the accepted research material. The traditional publishing functions of copy editing and scientific copy editing remain important to researchers in these disciplines. The traditional printed volume is of little interest, but the scientists highlighted the long-term electronic archiving of the journal content as important.

The initial results from this survey suggest that scientists in the fields of astrophysics and cosmology are, in the main, positioned positively towards a new publishing model that, in a respondent's own words, "...is more open, flexible, quicker (and cheaper?), and as "safe" or safer (i.e. ensuring science quality) as would be needed". A full examination of these results, together with the other findings from the RIOJA project, is expected to enrich our understanding of the many issues around the acceptance and sustainability of the overlay journal as a potential publishing model.

\section{References}

Ginsparg, P. (1996). Winners and Losers in the Global Research Village. Invited contribution, UNESCO Conference HQ, Paris, 19-23 Feb 1996.

Available at: http://xxx.lanl.gov/blurb/pg96unesco.html (Last accessed 20/01/2008)

Haggemann, M. (2006). SPARC Innovator: December 2006. Available at: http://www.arl.org/sparc/innovator/hagemann.html (Last accessed 20/0/1/2008)

Halliday, L and C Oppenheim. (1999). Economic models of the Digital Library. Available at: http://www.ukoln.ac.uk/services/elib/papers/ukoln/emod-diglib/final-report.pdf (Last accessed 20/01/2008)

Prosser, David C. (2005) Fulfilling the promise of scholarly communication - a comparison between old and new access models, in Nielsen, Erland Kolding and Saur, Klaus G. and Ceynowa, Klaus, Eds. Die innovative Bibliothek : Elmar Mittler zum 65.Geburtstag, pp. 95-106. K G Saur. (Also available at http://eprints.rclis.org/archive/00003918) (Last accessed 20/01/2008)

Smith, J W T. (1999). The deconstructed journal: a new model for academic publishing. Learned Publishing, Vol. 12 (2), pp. 79-91

The Times Higher Education Supplement. (2006). World's top 100 in science. Available at: http://www.thes.co.uk/statistics/international_comparisons/2006/top_100 science.aspx (Last accessed 31/08/2007)

The Times Higher Education Supplement. (2006). World's top non university institutions in science. Available

http://www.thes.co.uk/statistics/international comparisons/2006/top non unis science.aspx

(Last $\quad$ accessed $31 / 08 / 2007$ )

